\title{
Detection of Epstein-Barr Virus in Rapidly Growing Fibroadenomas of the Breast in Immunosuppressed Hosts
}

\author{
Celina G. Kleer, M.D., Michael D. Tseng, David E. Gutsch, M.D., Rosemary A. Rochford, Ph.D., \\ Zhifen Wu, M.D., Lynn K. Joynt, M.D., Mark A. Helvie, M.D., Tammy Chang, \\ Kenneth L. van Golen, Ph.D., Sofia D. Merajver, M.D., Ph.D. \\ Department of Pathology (CGK), Internal Medicine, Division of Hematology/Oncology (MDT, ZW, TC, \\ $K L \nu G, S D M)$, Division of Infectious Disease (DEG), Department of Epidemiology (RAR), and Department of \\ Radiology (LKJ, MAH), University of Michigan, Ann Arbor, Michigan
}

Fibroadenomas are the most common benign tumors of the female breast and are associated with a slight increase in the risk of subsequent breast cancer. Multiple fibroadenomas have been described in patients after renal transplantation and are thought to be secondary to drug-related growth stimulation. Epstein-Barr virus (EBV) has been detected in many neoplasms, including breast cancer. We set out to investigate whether EBV plays a role in the development of rapidly growing fibroadenomas in immunocompromised patients. We studied 19 fibroadenomas and one invasive ductal carcinoma that developed after organ transplantation or treatment for lupus erythematosus. As a control group we included 11 fibroadenomas from non-immunocompromised patients. DNA was amplified using polymerase chain reaction (PCR) of the EBV-encoded small RNA (EBER-2) DNA sequence. EBV latent membrane protein 1 (LMP-1) transcripts were amplified using reverse transcription (RT) PCR. Immunohistochemical (IHC) staining for LMP-1 protein was performed. A total of 9 out of 20 tumors (45\%) were concordantly positive by PCR and IHC. IHC stained exclusively the epithelial cells. All the fibroadenomas in non-immunocompromised patients were negative for LMP-1 (Fisher's exact test $P=\mathbf{. 0 0 0 6}$ ). These data suggest that EBV is associated with fibroadenomas in this immunosuppressed population and that the infection is specifically local-

Copyright (C) 2002 by The United States and Canadian Academy of Pathology, Inc.

VOL. 15, NO. 7, P. 759, 2002 Printed in the U.S.A.

Date of acceptance: April 9, 2002.

Work supported in part by DOD grants DAMD17-00-1-0636 (CGK), DAMD17-00-0345 (SDM), and NIH grant R01CA77612 (SDM).

Address reprint requests to: Celina G. Kleer, M.D., Department of Pathology, 2G332 University Hospital, 1500 E. Medical Center Drive, Ann Arbor, MI 48109-0054; e-mail: kleer@umich.edu; fax: 734-763-4095. ized to epithelial cells. This is the first study suggesting a role for $\mathrm{EBV}$ in the pathogenesis of fibroadenomas.

KEY WORDS: Breast, Epstein-Barr virus, Fibroadenoma.

Mod Pathol 2002;15(7):759-764

Epstein-Barr virus (EBV) is a common human $\gamma$-herpes virus estimated to have infected about $95 \%$ of the adult population worldwide. Despite the widespread prevalence of EBV infection, EBV has been directly implicated in the development of only two malignancies observed in relatively restricted geographic areas: Burkitt's Lymphoma in East Africa and nasopharyngeal carcinoma in Southern China. It has also been closely associated to Hodgkin's Disease, thymic lymphoepithelioma, opportunistic B-cell lymphomas, pleural B-cell lymphomas or pyothorax associated B-cell lymphomas, opportunistic T-cell and NK-cell lymphomas in immunodeficiencies, primary nasal T-cell and NK-cell lymphomas, gastric carcinoma, and most recently, invasive breast carcinoma (1-9).

As the number of possible associations between $\gamma$-herpes viruses and human cancer continues to grow, the question of whether the individual's immune-response status is a predisposing factor for virally mediated neoplasms emerges. Patients with suppressed immune systems from HIV infection or post-organ transplant immunosuppressive drugs are important groups in whom to study viral carcinogenesis. Kaposi sarcoma, now known to be caused by human herpes virus-8 (HHV-8), is an AIDS-defining malignancy (10). Forty to $66 \%$ of transplant patients develop skin cancer within 20 years of the transplant procedure, presumably because cellular immunosuppression provides an opportunistic environment for cancer-associated vi- 
ruses (11). EBV-positive B-cell lymphomas are also present in about $20-30 \%$ of AIDS patients (12).

Fibroadenomas are benign breast tumors that have been associated with a slight increased risk of breast cancer $(13,14)$. The observation of rapidly growing fibroadenomas in immunosuppressed patients suggests a possible viral cofactor in the pathogenesis of benign breast neoplasms. In this study, we set out to test the hypothesis that EBV plays a role in the development of fibroadenomas in immunocompromised patients.

\section{MATERIALS AND METHODS}

\section{Patient Sample Selection}

Twenty patients with rapidly growing tumors of the breast were identified. The identification of rapidly growing was performed using mammographic evaluation. All the patients had masses growing faster than expected on mammograms from year to year. As controls, identified a group of 11 fibroadenomas in non-immunosuppressed patients. The formalin-fixed, paraffin-embedded breast tissues were retrieved from the Pathology files at the University of Michigan. The cases included 19 fibroadenomas and one invasive ductal carcinoma. Tissues were obtained by core biopsy (three cases) or by open biopsy (17 cases). All patients were either taking immunosuppressive drugs to prevent organ graft rejection or to control systemic lupus erythematosus. After selection, the tissues were stripped of identifiers referable to the patients.

\section{DNA Extraction}

Blocks were cut into sections and mounted on glass slides for analysis. Laser capture microdissection (LCM) technique was used for DNA extraction as previously described (15). Paraffin sections were deparaffinized, dehydrated, and stained with eosin. Individual tumor epithelial cells were microdissected off each section using a PixCell II LCM system (Arcturus, Mountain View, CA). Laser pulses were used to fuse individual cells onto the surface of transfer film/microcentrifuge tube caps. Digestion buffer $(0.04 \%$ Proteinase K, $10 \mathrm{~mm}$ Tris-HCL (pH 8.0), 1 mм EDTA, and 1\% Tween-20) was added to the tubes. The capped tubes were inverted and incubated overnight at $37^{\circ}$ C. Samples were boiled for 5 minutes at $95^{\circ} \mathrm{C}$ and, if not used immediately, stored at $-20^{\circ} \mathrm{C}$. As positive control we used DNA from a known EBV-positive testicular lymphoma.

\section{PCR Amplification}

Primers for the EBV-encoded small RNA (EBER-2) DNA sequence were synthesized as previously described (5'-CCCTAGTGGTTTCGGACACA-3' sense primer and 5'-ACTTGCAAATGCTCTAGGCG-3' antisense primer) (2). PCR reagents and reaction protocols were tested using pilot runs with DNA extracted from an EBV-positive testicular lymphoma. Singleround PCR of our LCM-extracted tumor DNA (15 $\mu \mathrm{L})$ were then performed using the following conditions: denaturation at $95^{\circ} \mathrm{C}$ (5 minutes), followed by 40 cycles of denaturation at $95^{\circ} \mathrm{C}$ (30 seconds), annealing at $58^{\circ} \mathrm{C}$ ( 1 minute), and extension at $72^{\circ} \mathrm{C}(2$ minutes). The cycle was followed by a 7 minute extension at $72^{\circ} \mathrm{C}$.

To determine whether the extracted DNA was technically suitable for PCR amplification, a region of the beta-tubulin gene sequence was concurrently amplified (5'-AAATTTTAACCATGAGGGAAATC-3' sense primer and 5'-GTGGGGTCGATGCCATGT-3' anti-sense primer). Single-round PCR was performed as follows: denaturation at $95^{\circ} \mathrm{C}(5 \mathrm{~min}-$ utes), followed by 35 cycles of denaturation at $95^{\circ} \mathrm{C}$ (1 minute), annealing at $58^{\circ} \mathrm{C}$ (1 minute), and extension at $72^{\circ} \mathrm{C}$ ( 2 minutes), ending with a 7 minute extension at $72^{\circ} \mathrm{C}$. Both EBER-2 and beta-tubulin PCR products were separated on a $2.5 \%$ agarose gel by electrophoresis and visualized with ethidium bromide under UV light.

\section{RT-PCR Amplification}

Tissue was scraped off paraffin embedded sections and onto siliconized $2.0 \mathrm{ml}$ microcentrifuge tubes (Life Science Products, Denver, CO) for RNA extraction. Two slides were scraped for each sample, deparaffinized in xylene and washed in ethanol. After centrifugation at 20,800 RCF for $10 \mathrm{~min}$ utes, Trizol RNA isolation reagent (Life Technologies, Rockville, MD) was added to the dried pellets. Tubes were then incubated at $65^{\circ} \mathrm{C}$ for 10 minutes. Sample tubes were placed on ice and E. coli tRNA (Roche, Basel, Switzerland) was added. The samples were mixed vigorously with chloroform and incubated for 3 minutes. The microcentrifuge tubes were centrifuged again at $4^{\circ} \mathrm{C}$ for 15 minutes $(15,300 \mathrm{RCF})$. The clear aqueous phase was transferred to an RNase-free microcentrifuge tube. RNA was then precipitated in isopropanol and centrifuged for $4^{\circ} \mathrm{C}$ for 10 minutes. The pellet was washed in $75 \%$ ethanol, $100 \%$ ethanol, and resuspended in Diethyl Pyrocarbonate-treated distilled and deionized water (DEPC $\left.\mathrm{ddH}_{2} 0\right)$. Samples were stored at $-80^{\circ} \mathrm{C}$. RNA was also extracted from an EBV-positive testicular lymphoma to serve as a positive control.

A one-tube reverse-transcription/cDNA amplification method followed by a nested cDNA PCR amplification was used. Nested primers (5'ATCTTCGGGTGCTTACTTG-3' external sense, 5'AAGGCCAAAAGCTGCCAGATGGTGGC-3' external anti-sense, 5'-CATTGTTCCTTGGAATTGTGCTGT- 
TC-3' internal sense, and a 5'-ACCAAGTCGCCAGAGCATC-3' internal anti-sense) were designed to span an intron in the EBV genome, so amplification of cDNA would yield a different size band than amplification of genomic DNA.

An initial PCR reaction mix of 0.2 mm DNTPs, $1 \mathrm{X}$ PCR buffer (Promega, Madison, WI), $1.4 \mathrm{~mm} \mathrm{MgCl}_{2}$, $10 \mathrm{ng} / \mu \mathrm{l}$ sense and anti-sense LMP-1 primers, and DEPC $\mathrm{ddH}_{2} 0$ was made. Before each reaction, 2.5 U/rxn Taq polymerase (Promega), $12.5 \mathrm{U} / \mathrm{rxn} \mathrm{Re}-$ verse Transcriptase AMV (Roche), $40 \mathrm{U} /$ rxn RNase Inhibitor (Roche) were combined with the initial PCR reaction mix. This final reaction mix was then aliquoted to individual reaction tubes and sample RNA was added. The solution was then cycled through the following steps: a reverse transcription at $42^{\circ} \mathrm{C}$ (30 minutes), denaturation at $95^{\circ} \mathrm{C}(4$ minutes), and 35 cycles of $95^{\circ} \mathrm{C}$ ( 1 minute), $57^{\circ} \mathrm{C}(2$ minutes), $72^{\circ} \mathrm{C}(2 \mathrm{~min})$, followed by a final extension of $72^{\circ} \mathrm{C}$ ( 7 minutes). After completion of the RT-PCR reaction, $5 \mu \mathrm{l}$ of cDNA product was used in a nested PCR reaction with internal primers. They were then cycled through the same program as previously described for the tubulin PCR reactions. Products were separated on a 2.5\% agarose gel and visualized with ethidium bromide under UV light. pronase (DAKO) to break down formalincrosslinking. The samples were counterstained in Mayer's Haemtatoxylin (DAKO) for 5 minutes and dipped 10 times into $37 \mathrm{~mm}$ ammonia. Slides were then treated with aqueous crystal mounting medium (Biomeda) and coverslipped with Permount (Fisher). Sections from a paraffin-embedded EBVpositive hu-PBL-SCID lymphoma were stained as positive controls. Appropriate negative controls were used in each run.

\section{RESULTS}

\section{Clinical Findings and Histologic Study}

Table 1 summarizes the clinicopathologic information. All patients were women, ages 21 to 65 at the time of diagnosis. Examination of hematoxylin and eosin stained sections revealed that 19 of the 20 tumors were fibroadenomas with classic histologic features of elongated and attenuated ducts, compressed by a fibrous proliferating stroma (Fig. 2A and B). The single case of carcinoma was an invasive ductal carcinoma with associated ductal carcinoma in situ. None of the cases had prominent lymphocytic infiltrates.

\section{Immunohistochemistry}

A DAKO LSAB2 HRP (DAB) staining kit was used for LMP-1 immunohistochemistry (IHC). Samples were analyzed with primary mouse monoclonal antibodies recognizing four distinct LMP-1 epitopes (DAKO) according to the manufacturer's instructions. Paraffin embedded sections were first deparaffinized twice in xylene for 5 minutes, then rehydrated for 3 minutes in absolute ethanol twice and $95 \%$ ethanol twice. Sections were pretreated with

\section{Detection of EBV-Specific Sequences and} Protein

Thirteen of the $18(72 \%)$ fibroadenomas were positive for EBER-2 sequence (Table 1, Fig. 1). Amplification of the tubulin gene confirmed that the DNA was suitable for PCR amplification. EBER-2 DNA sequence was successfully amplified from the extracted DNA of a paraffin-embedded EBVpositive testicular lymphoma. The water control (in which no sample DNA was added) did not yield a

TABLE 1. Clinicopathologic Information

\begin{tabular}{|c|c|c|c|c|c|}
\hline Case & Clinical History & Pathologic Diagnosis & Age & EBER-2 PCR & LMP-1 IHC \\
\hline 1 & Kidney transplant & Fibroadenoma & 43 & NA & Pos \\
\hline 2 & Heart transplant & Fibroadenoma & 56 & Pos & Pos \\
\hline 3 & Kidney transplant & Fibroadenoma & 34 & Pos & Pos \\
\hline 4 & Lupus & Fibroadenoma & 44 & Pos & Pos \\
\hline 5 & Heart transplant & Fibroadenoma & 49 & Pos & Neg \\
\hline 6 & Kidney transplant & Fibroadenoma & 42 & Pos & Pos \\
\hline 7 & Kidney transplant & Fibroadenoma & 45 & Pos & Neg \\
\hline 8 & Heart transplant & Fibroadenoma & 43 & Pos & Pos \\
\hline 9 & Liver transplant & Fibroadenoma & 35 & Pos & Pos \\
\hline 10 & Lupus & Fibroadenoma & 25 & Pos & Pos \\
\hline 11 & Kidney transplant & Fibroadenoma & 21 & Neg & Pos \\
\hline 12 & Kidney transplant & Fibroadenoma & 26 & Pos & Pos \\
\hline 13 & Kidney transplant & Fibroadenoma & 25 & Neg & Pos \\
\hline 14 & Heart transplant & Fibroadenoma & 53 & Pos & Neg \\
\hline 15 & Heart transplant & Fibroadenoma & 53 & Pos & Pos \\
\hline 16 & Liver transplant & Invasive ductal carcinoma & 65 & NA & Neg \\
\hline 17 & Kidney transplant & Fibroadenoma & 44 & Neg & Neg \\
\hline 18 & Kidney transplant & Fibroadenoma & 44 & Pos & Neg \\
\hline 19 & Kidney transplant & Fibroadenoma & 44 & Neg & Neg \\
\hline 20 & Kidney transplant & Fibroadenoma & 44 & Neg & Neg \\
\hline
\end{tabular}


product, indicating the reaction was free of contamination, an important concern in this experiment.

Fourteen tumors were analyzed by nested RTPCR for LMP-1 RNA. RNA extracted from an EBVpositive testicular lymphoma was amplified simultaneously with the samples, controlling for the RNA extraction technique, PCR conditions, and reagents. The primers were designed to target an intron sequence to yield an expected product of 258-bp. In contrast, amplification of LMP-1 DNA contamination was expected to produce a 333-bp product, and thus, easily recognized. Although the testicular lymphoma consistently displayed the expected RNA band, none of the breast fibroadenoma samples showed evidence of LMP-1 RNA, likely due to minute yields of this RNA species.

All 20 tumors from immunocompromised patients and 11 tumors from non-immunocompromised patients were immunohistochemically stained with antibodies for LMP-1. Results were scored independently by two investigators. The hu-PBL-SCID lymphoma control consistently displayed strong staining of the EBV-transformed human lymphocytes. As expected, surrounding mouse tissue did not stain positively for LMP-1. Twelve fibroadenomas from immunocompromised patients $(60 \%)$ expressed LMP-1 protein in the cytoplasm of the epithelial cells (Fig. 2). The single case of invasive ductal carcinoma was negative for LMP-1. All fibroadenomas from nonimmunocompromised patients were negative (Fisher's exact test, $P=.0006$ ). Adipocytes, normal breast lobules and stromal cells were negative in all cases. Table 1 summarizes the results of EBER-2 PCR, LMP-1 RT-PCR, and LMP-1 immunohistochemistry.

\section{DISCUSSION}

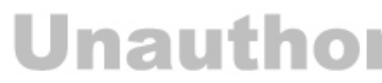

Although the correlation between EBV and lymphoproliferative disorders is strongest, EBV has also been associated with several cancers of epithelial origin, such as nasopharyngeal carcinoma and gastric carcinoma $(1,2,9)$. In addition, EBV has long been suspected to play a role in human breast carcinogenesis. The presence of a mouse mammary tumor virus in rodents and published reports of HIV-positive rapidly growing breast cancers suggest a possible viral etiology for some breast cancers (10, 16). One study reported multiple and bilateral fibroadenomas in immunosuppressed patients receiving cyclosporin A (17). Isolated studies have investigated the EBV/breast cancer association with contradictory results $(2,18,19)$.

This is the first study to investigate the role of EBV in rapidly growing breast tumors in immunocompromised patients. We detected the EBV ge- nome, through PCR amplification of EBER-2 DNA, in 13 of 18 (72\%) tumors (Fig. 1), and LMP-1 protein in 12 of $20(60 \%)$ (Fig. 2) of the tumors studied. The fact that none of the tumors had lymphocytic infiltration minimizes the possibility that the positive EBER-2 results were due to contaminating lymphocytes. Nine tumors (45\%) were concordantly positive for both, EBER-2 DNA and LMP-1 protein. None of the fibroadenomas from nonimmunosuppressed patients expressed LMP-1 protein (Fisher's exact test $P=.0006$ ). Therefore, we conservatively estimate that EBV is associated with the development of fibroadenomas in immunocompromised patients in $45 \%$ of the cases but not in non-immunocompromised patients. We did not, however, detect LMP-1 RNA in our samples using nested RT-PCR. This was likely due to the low sensitivity of our assay and the paucity of RNA material extracted from tumor sections. Although our protocol was developed from several published reports of RNA isolation from paraffin embedded tissues, we were unsuccessful in determining whether our extracted RNA was technically suitable for PCR and thus, we were unable to replicate in our samples previously published results (20). The projected yield of RNA for each sample was so marginal that co-amplification of tubulin RNA would have jeopardized the RT-PCR of LMP-1 RNA. It is also possible that levels of LMP-1 message are too low in fibroadenomas to be detected through RT-PCT, yet are sufficient to translate proteins and participate in the pathogenesis of fibroadenomas.

We have established for the first time an association between EBV infection and fibroadenomas of the breast in immunosuppressed patients. The mechanism by which EBV may be implicated in breast tumorigenesis has not been elucidated. It appears from the epidemiologic literature that EBV infection alone is not sufficient for breast tumor development in humans. This assertion is consistent with the existence of EBV-positive benign breast tumors. In this study, we localized EBV to epithelial cells within tumor samples. It is possible, that EBV converts the epithelial cells to a preneo-

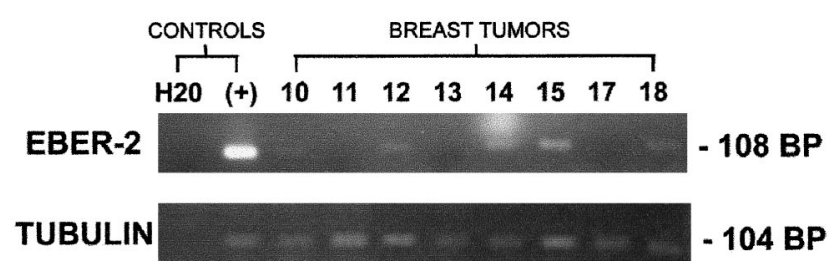

FIGURE 1. Detection of Epstein-Barr virus genome by PCR amplification of the 108-bp EBV-encoded small RNAs (EBER-2) fragment. A 104-bp b-tubulin sequence was amplified to verify the presence of genomic DNA in each sample extraction. $\mathrm{H}_{2} \mathrm{O}=$ water control without DNA and $(+)=\mathrm{EBV}$-positive control (testicular lymphoma). Samples 10, 12, 14, 15, and 18 = positive tumors; 11,13 , and $17=$ negative tumors. 

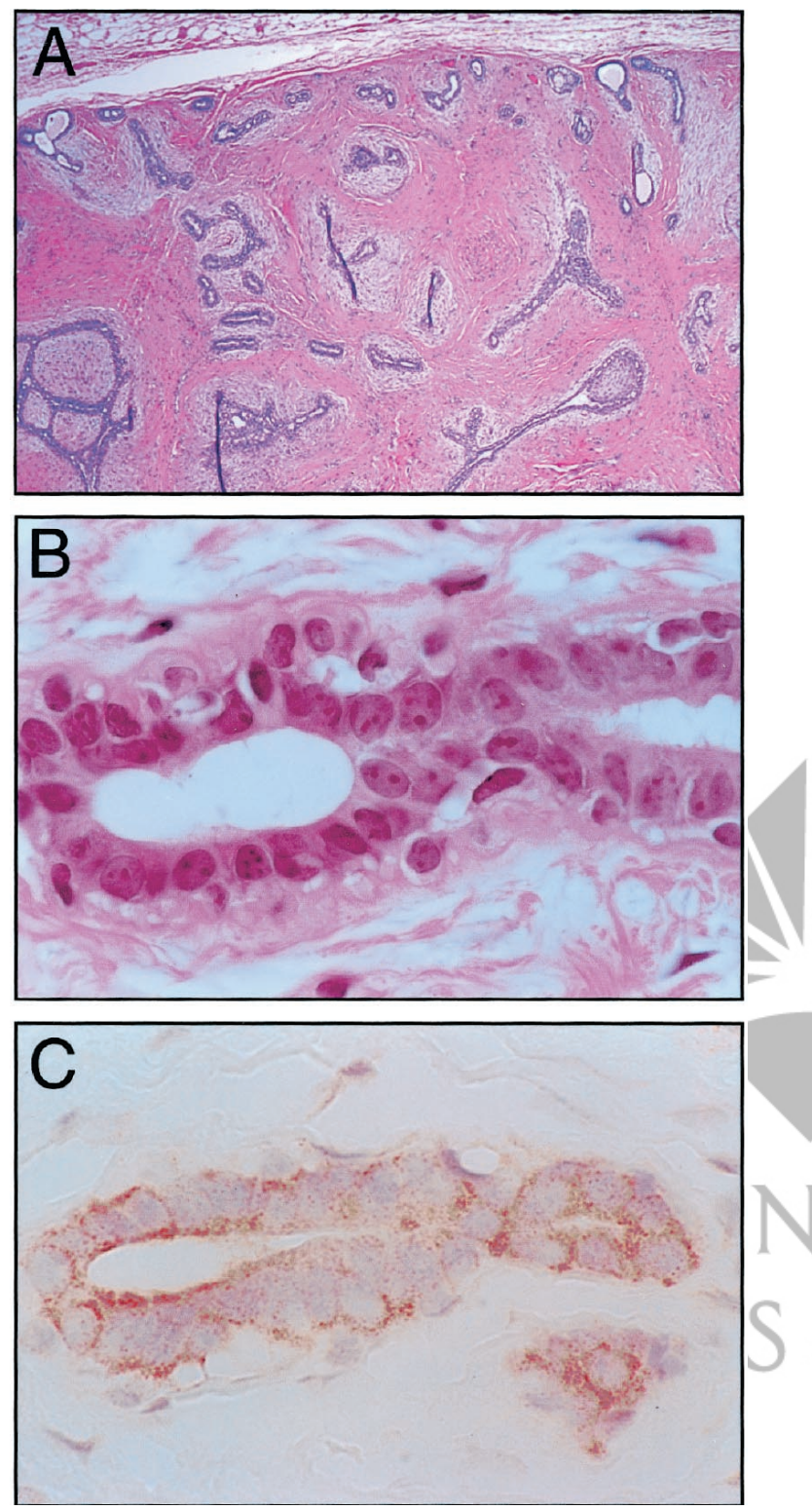

FIGURE 2. A, Low power $(100 \times)$ photograph of a fibroadenoma in an immunocompromised patients. There are no distinctive histologic features; B, High power $(400 \times)$ picture of a duct in this fibroadenoma. C, Same fibroadenoma with cytoplasmic immunostaining for LMP-1 $(400 \times)$. Note the positive membrane associate LMP-1 staining in the ductal epithelial cells and the negatively stained stromal fibroblasts.

plastic state through increased proliferation of epithelial cells in a similar way that EBV induces immortalization of B-lymphocytes $(1,21)$.

Although we did not set out specifically to do so, our results may help reconcile some of the conflicting results from previous studies that investigated EBV in breast tumors. Among our samples, a significant proportion (72\%) were positive by at least one technique (EBER-2 PCR). In the Bonnet (2) and Labreque (18) studies, in which they demonstrated the presence of EBV genome using PCR, only a handful of samples were analyzed by another EBV detection technique such as IHC. In the negative studies of Chu et al. $(22,23)$ and Glasser et al. (19),
EBER-2 PCR amplification was not performed. Our results show that different EBV detection techniques often display seemingly contradictory results, possibly because their sensitivity depends on sample-specific preparation at the time of fixation, or subsequent alterations of the specimens over time. The difference between previous studies showing positive and negative associations between EBV and breast cancer may be due to choice and number of detection modalities. Therefore, although EBV-mediated breast cancers may have different patterns of EBV-specific gene expression than EBV-mediated fibroadenomas, our data suggest that future studies of this kind should involve at least two EBV screening approaches to confirm potential associations.

In conclusion, we have demonstrated that EBV is specifically present in the epithelial cells of a welldefined subset of breast tumors. This is the first study to show the association between EBV and benign breast neoplasms. Furthermore, the localization of EBV exclusively in the tumor epithelial cells suggests that EBV may play a causative role in the development of breast fibroadenomas in immunosuppressed patients.

\section{REFERENCES}

1. Okano M, Osato T, Koizumi S, Imai S, Aya T, Fujiwara S, et al. Epstein-Barr virus infection and oncogenesis in primary immunodeficiency. AIDS Res 1986;2(Suppl 1):S115-9.

2. Bonnet M, Guinebretiere JM, Kremmer E, Grunewald V, Benhamou E, Contesso G, et al. Detection of Epstein-Barr virus in invasive breast cancers. J Natl Cancer Inst 1999;91: 1376-81.

3. Kumar S, Fend F, Quintanilla-Martinez L, Kingma DW, Sorbara L, Raffeld M, et al. Epstein-Barr virus-positive primary gastrointestinal Hodgkin's disease: association with inflammatory bowel disease and immunosuppression. Am J Surg Pathol 2000;24:66-73.

4. Morand P, Buisson M, Collandre H, Chanzy B, Genoulaz O, Bourgeat MJ, et al. Human herpesvirus 8 and Epstein Barrvirus in a cutaneous B-cell lymphoma and a malignant cell line established from the blood of an AIDS patient. Leuk Lymphoma 1999;35:379-87.

5. Takeshita M, Yamamoto M, Kikuchi M, Kimura N, Nakayama J, Uike N, et al. Angiodestruction and tissue necrosis of skin-involving CD56 + NK/T-cell lymphoma are influenced by expression of cell adhesion molecules and cytotoxic granule and apoptosis-related proteins. Am J Clin Pathol 2000;113:201-11.

6. Ohga S, Kanaya Y, Maki H, Takada H, Ohshima K, Kanda M, et al. Epstein-Barr virus-associated lymphoproliferative disease after a cord blood transplant for Diamond-Blackfan anemia. Bone Marrow Transplant 2000;25:209-12.

7. Perez-Valles A, Sabater-Marco V, Carpio-Manez D, BotellaEstrada R, Nogueira-Vasquez E, Martorell-Cebollada M. Extranodal peripheral T-cell lymphoma with angiocentric growth pattern and Epstein-Barr viral DNA associated affecting paratesticular soft tissue. J Cutan Pathol 2000;27:80-6.

8. Durmaz R, Aydin A, Koroglu M, Durmaz B, Ciralik H. Investigation of the relationship between Epstein-Barr virus and 
ordinary gastric carcinoma using the nested polymerase chain reaction. Acta Virol 1998;42:359-63.

9. Herrera-Goepfert R, Reyes E, Hernandez-Avila M, Mohar A, Shinkura R, Fujiyama C, et al. Epstein-Barr virus-associated gastric carcinoma in Mexico: analysis of 135 consecutive gastrectomies in two hospitals. Mod Pathol 1999;12:873-8.

10. Guth AA. Breast cancer and HIV: what do we know? Am Surg 1999;65:209-11.

11. de Villiers EM. Human papillomavirus infections in skin cancers. Biomed Pharmacother 1998;52:26-33.

12. Beral V, Peterman T, Berkelman R, Jaffe H. AIDS-associated non-Hodgkin lymphoma. Lancet 1991;337:805-9.

13. Levi F, Randimbison L, Te VC, La Vecchia C. Incidence of breast cancer in women with fibroadenoma. Int J Cancer 1994;57:681-3.

14. Dupont WD, Page DL, Parl FF, Vnencak-Jones CL, Plummer WD Jr, Rados MS, et al. Long-term risk of breast cancer in women with fibroadenoma. N Engl J Med 1994;331:10-5.

15. Bonner RF, Emmert-Buck M, Cole K, Pohida T, Chuaqui R, Goldstein S, et al. Laser capture microdissection: molecular analysis of tissue. Science 1997;278:1481, 1483.

16. Labat ML. Possible retroviral etiology of human breast cancer. Biomed Pharmacother 1998;52:6-12.
17. Baildam AD, Higgins RM, Hurley E, Furlong A, Walls J, Venning MC, et al. Cyclosporin A and multiple fibroadenomas of the breast. Br J Surg 1996;83:1755-7.

18. Labrecque LG, Barnes DM, Fentiman IS, Griffin BE. EpsteinBarr virus in epithelial cell tumors: a breast cancer study. Cancer Res 1995;55:39-45.

19. Glaser SL, Ambinder RF, DiGiuseppe JA, Horn-Ross PL, Hsu JL. Absence of Epstein-Barr virus EBER-1 transcripts in an epidemiologically diverse group of breast cancers. Int J Cancer 1998;75:555-8.

20. Mundle S, Allampallam K, Aftab Rashid K, Dangerfield B, Cartlidge J, Zeitler D, et al. Presence of activation-related m-RNA for EBV and CMV in the bone marrow of patients with myelodysplastic syndromes. Cancer Lett 2001;164:197205.

21. Mizuno F, Aya T, Osato T. Growth in semisolid agar medium of human cord leukocytes freshly transformed by EpsteinBarr virus. J Natl Cancer Inst 1976;56:171-3.

22. Chu JS, Chen CC, Chang KJ. In situ detection of Epstein-Barr virus in breast cancer. Cancer Lett 1998;124:53-7.

23. Chu PG, Chang KL, Chen YY, Chen WG, Weiss LM. No significant association of Epstein-Barr virus infection with invasive breast carcinoma. Am J Pathol 2001;159: 571-8.
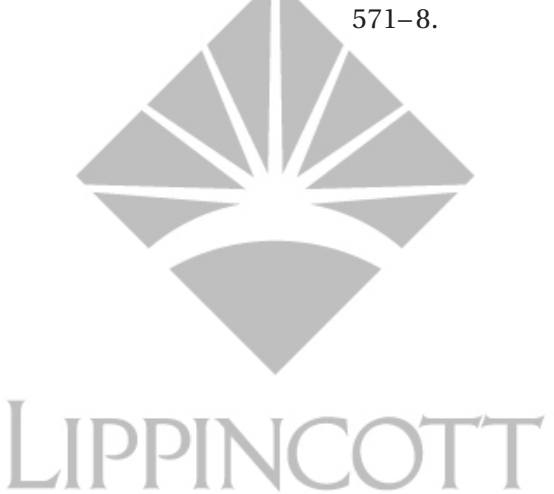

WILLIAMS \& WILKINS

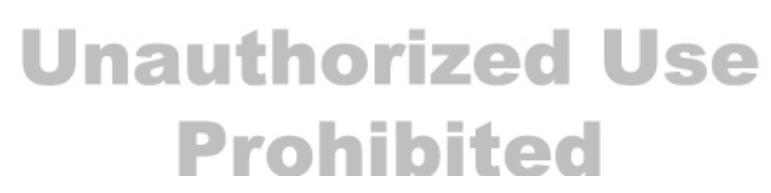

